\title{
MODELO CALGARY DE AVALIAÇÃO DA FAMÍLIA DE RECÉM-NASCIDOS: ESTRATÉGIA PEDAGÓGICA PARA ALUNOS DE ENFERMAGEM
}

Calgary Evaluation's Model of the Newborn's Family: Pedagogical Strategies for Nursing Students

Modelo Calgary de Evaluación de la Familia del Recién Nacido: Estrategia Pedagógica para Alumnos de Enfermería

\section{Resumo}

Trata-se de um relato de experiência, cujo objetivo é descrever a experiência da utilização do Modelo Calgary de Avaliação e Intervenção Familiar na consulta de enfermagem à criança. Os resultados evidenciaram que esse modelo pode ser utilizado a partir da segunda consulta, quando se inicia um vínculo entre docente-discentes e família, que são necessários mais de cinco encontros e que a duração da entrevista é de, no mínimo, 20 minutos. 0 modelo utilizado como estratégia de ensino-aprendizagem permitiu aos alunos uma maior reflexão sobre os problemas apresentados pela família numa relação de diálogo, mudanças de autoconhecimento e de estrutura familiar, melhor compreensão da rede familiar e como a cultura familiar influencia as práticas de cuidado prestado à criança no domicílio.

Palavras-chave: Consulta de Enfermagem. Educação em Saúde. Saúde da Criança. Família.

\begin{abstract}
It is about an experience report, which aimed to describe the experience of using the Calgary Model of Evaluation and intervention of the Family in the nursing consultation to the child. The results showed that this model could be used from the second consultation, when begins a link among the teachers, students and family, and five more encounters are necessary and the duration of the interview must be at least 20 minutes. The used model as strategy of learn and teaching allowed to the students a better reflection about the problem presented by the family related to the dialog, self knowledge changes and in the family structure, better understanding of the family net and how a family culture influences the care practice gave to the child at home.
\end{abstract}

Keywords:

Nursing Consultation. Health Education. Child Health. Family.

\section{Resumen}

Es un relato de experiencia, cuyo objetivo es describir la experiencia del uso del Modelo Calgary de Evaluación e Intervención Familiar en la consulta de enfermería al niño. Los resultados evidenciaran que ese modelo puede ser usado a partir de la segunda consulta, cuando es iniciado un lazo entre docente-alumno y familia, que son necesarios más de cinco encuentros y que la duración de la entrevista es de, en el mínimo, 20 minutos. El modelo usado como estrategia de enseñanza-aprendizaje permitió a los alumnos una mayor reflexión sobre los problemas presentados por la familia en una relación de diálogo, cambios de auto conocimiento y de estructura familiar, mejor comprensión de la red familiar y como la cultura de la familia influencia las prácticas de cuidado prestadas a los niños en el domicilio.

Palabras clave: Consulta de Enfermería. Educación en Salud. Salud del Niño. Familia.

'Enfermeira Especialista em Pediatria. Professora Adjunta do Departamento Materno-Infantil da Escola de Enfermagem Anna Nery/UFRJ. Membro do Núcleo de Pesquisa em Saúde da Criança/EEAN-UFRJ. ${ }^{2}$ Professora Assistente do Departamento Materno-Infantil da Faculdade de Enfermagem da UERJ. Doutoranda da Escola de Enfermagem Anna Nery/UFRJ. Membro dos Núcleos de Pesquisa Saúde da Criança e do Adolescente/NUSCRIAD e Núcleo de Pesquisa em Saúde da Criança/EEAN-UFRJ. ${ }^{3}$ Professor Assistente do Departamento Materno-Infantil da Faculdade de Enfermagem da UERJ. Pesquisador do Núcleo de Saúde da Criança e Adolescente/NUSCRIAD. 


\section{INTRODUÇÃO}

0 Curso de Graduação em Enfermagem da Faculdade de Enfermagem da Universidade do Estado do Rio de Janeiro/ FENF-UERJ possui diversos projetos de extensão, entre eles 0 projeto intitulado "Consulta de Enfermagem Neonatal - uma alternativa para a assistência".

Esse projeto é realizado por docentes da Subárea Assistencial Saúde da Criança V do Departamento de Enfermagem Materno-Infantil (DEMI) em parceria com profissionais de saúde de um Centro Municipal de Saúde do Rio de Janeiro e tem como objetivo primordial o desenvolvimento de uma nova modalidade de ensino-aprendizagem diferenciada da tradicionalmente observada no DEMI/FEUERJ, antes de 1997. A partir dessa data, passamos a buscar um ensino de enfermagem que valorizasse não somente o cuidar da saúde do recém-nascido no ambiente hospitalar, mas também nos espaços extra-hospitalares, como centros municipais de saúde, creches e comunidades.

Os internos de enfermagem do $8^{\circ}$ período participam desse projeto de extensão prestando assistência ao recém-nascido, levando em consideração sua totalidade, singularidade e sua inserção no contexto histórico-social, bem como as diretrizes contidas nas políticas públicas de atenção à saúde da criança ${ }^{1}$. Sendo assim, procuramos desenvolver no aluno um olhar que valorize o cuidado de enfermagem à criança e sua família.

Na prática assistencial da enfermagem, a família é considerada um sistema familiar, faz parte de um suprasistema mais amplo, composto de muitos subsistemas, como pais-filhos, cônjuge e irmãos. Além disso, a família é envolvida por diversos supra-sistemas mais amplos, como vizinhanças, organizações ou comunidades religiosas ${ }^{2-4}$.

Como docentes, acreditamos que o conceito de família refere-se a todos aqueles indivíduos que são considerados pelos próprios membros da família importantes para a unidade familiar, incluindo parentes, amigos e outros grupos sociais: a escola, a igreja.

Sendo assim, sentimos a necessidade de utilizar, no espaço da consulta de enfermagem, um instrumento para a sistematização da assistência no atendimento ao recémnascido e sua família. Para tanto, buscamos implementar nas consultas o Modelo Calgary de Avaliação (MCAF) e Intervenção (MCIF) Familiar.

A opção de trabalhar com o Modelo Calgary de Avaliação de Famílias (MCAF) parte das várias avaliações realizadas por alunos de graduação e da especialização em enfermagem neonatal, que verbalizaram como sugestão ao término das disciplinas, além das percepções dos professores envolvidos. A cada semestre sentíamos a necessidade de ter um instrumento que melhor pudesse compreender as relações afetivas mãe / criança / família, assim como as interferências culturais familiares no cuidado prestado ao recém-nascido no domicílio e a rede de suporte social. Ao fazermos uma busca nos principais periódicos de enfermagem, encontramos alguns estudos ${ }^{4-10}$ realizados na enfermagem que utilizam o MCAF e MCIF.

Diante do exposto, foi estabelecido como objetivo: descrever a experiência da utilização do Modelo Calgary de Avaliação (MCAF) e Intervenção (MCIF) Familiar na consulta de enfermagem à criança.

\section{APRESENTAÇÃO DO MODELO CALGARY DE AVALIAÇÃO (MCAF) E O MODELO CALGARY DE INTERVENÇÃO (MCIF) DA FAMÍLIA}

0 Modelo Calgary de Avaliação da Família2-4 é uma estrutura multidimensional que consiste em três categorias principais: estrutural, de desenvolvimento e funcional; cada categoria contém várias subcategorias que podem ser ou não avaliadas na primeira consulta, ou mesmo nunca ser avaliadas. 0 foco da avaliação familiar concentra-se mais na interação entre todos os membros da família.

$\mathrm{Na}$ avaliação estrutural, três subcategorias podem ser avaliadas: estrutura interna, externa e o contexto. Nessa categoria, a enfermeira que atende à criança examina quem faz parte da família, qual o vínculo afetivo entre seus membros e qual o seu contexto ${ }^{1-3}$.

A estrutura interna abrange seis subcategorias: composição familiar, gênero, orientação sexual, ordem de nascimento, subsistemas e limites, cujo roteiro de entrevista abarca: Composição familiar: Quem faz parte desta família? Quem a família considera como família? Há alguém que não tem parentesco biológico?; Gênero: Quais as idéias de seus pais sobre masculinidade e feminilidade? Como é a relação de cuidado com o filho? Como o companheiro se comporta diante do nascimento / amamentação / doença do seu filho?; Orientação sexual - atividade sexual; Ordem de nascimento: Quantos filhos? Qual o mais velho, quantos anos tem? Qual o próximo depois dele? Ocorreu algum aborto? A subcategoria de subsistemas abrange ainda as seguintes questões: identificar díades marido-mulher, mãe-filho, avó-neto; Qual o efeito que elas causam sobre o nível de estresse familiar?; Limites-regras na família para definir quem e como participa: Conversa com alguém quando se sente estressado?; Quem você procuraria quando se sentisse feliz ou triste?

A estrutura externa possui duas subcategorias: família extensa e sistemas mais amplos na família, que incluem a família de origem, de procriação, atual geração e membros da família adotiva. Família extensa: onde moram seus pais? Com que freqüência você tem contato com os pais? Como são seus irmãos? Qual de seus parentes é o mais próximo de você? A quem você ajuda quando pode? Você está disponível se eles precisarem de você? Sistemas mais amplos: esta subcategoria refere-se a instituições sociais mais amplas e pessoas com as quais as famílias têm contato significativo: quem são os profissionais de saúde envolvidos? Qual o relacionamento com a família e o sistema mais amplo? Com que regularidade interage? Estão envolvidos? Pouco envolvidos? A enfermeira é solicitada a assumir a responsabilidade por outra do sistema? 
Qual o conselho dos profissionais sobre o problema? Como está indo o relacionamento dos profissionais com a família?

0 contexto é explicado como a citação total ou as informações básicas relevantes a algum fato ou personalidade. Tendo em vista que o contexto permeia e circunscreve o indivíduo e a família, o contexto inclui cinco subcategorias: etnia, raça, classe social, religião e espiritualidade e ambiente. Pode-se perguntar à família: você pode falar sobre as práticas de cuidado ao seu filho existentes na sua família? 0 que significa saúde para você? Como você sabe que é saudável? Você pode me ajudar a entender o que preciso saber para melhor ajudá-lo? Existem diferenças no cuidado prestado/criação de seus filhos ou sua? Sua situação financeira influencia a utilização de recursos de saúde? Você mudou de casa várias vezes nos últimos anos? As mudanças na sua vida tiveram influências mais positivas ou negativas sobre a capacidade de lidar com o problema? A percepção profissional que atende você é diferente da sua? Quais serviços disponíveis são próximos de sua casa? Como você chegou até aqui? Como é seu relacionamento com a vizinhança?

Para a avaliação estrutural, dois instrumentos são utilizados para delinear as estruturas internas e externas da família: o Genograma ${ }^{2-4}$ e o Ecomapa ${ }^{2}$. Esses instrumentos foram desenvolvidos como dispositivos de avaliação, planejamento e intervenções familiares.

0 genograma é um diagrama que detalha a estrutura e 0 histórico familiar, tende a seguir gráficos convencionais genéticos e genealógicos. É uma árvore familiar representando a estrutura familiar interna. Geralmente incluem-se pelo menos três gerações, e os membros da família são colocados em séries horizontais que significam linhagens de geração. As crianças são denotadas por linhas verticais ${ }^{2-4}$.

Os homens são representados por quadrados, e as mulheres, por círculos, e cada membro é identificado pelo nome, idade e ocupação. 0 nome e idade da pessoa devem ser anotados do lado de dentro do quadrado ou círculo, deve-se colocar o ano da morte do familiar, ou aborto, e informar data da separação conjugal ${ }^{2-4}$.

A entrevista utilizando o genograma familiar faz com que a enfermeira obtenha compreensão e vínculos da família, tenha uma visão geral da estrutura da família. A maior vantagem do genograma é o seu formato gráfico, pois em poucos minutos o enfermeiro pode ter uma imagem da situação clínica da criança e sua família sem uma árdua procura em pilhas de notas ${ }^{2-4}$.

0 ecomapa é um diagrama que representa a visão geral da situação da família, retrata relaç̃̃es importantes de educação, ou conflitos entre família e o mundo. Demonstra o fluxo ou a falta de recursos ou privação. Coloca-se o genograma da família dentro de um círculo central e fazemse círculos externos representando pessoas, órgãos ou instituições no contexto familiar².

0 tamanho dos círculos não é importante. As linhas podem ser desenhadas entre as famílias e os círculos externos podem representar a natureza do vínculo afetivo existentes da família com a comunidade. Linhas indicam o tipo de conexão, linhas contínuas indicam fortes vínculos, linhas pontilhadas indicam vínculos frágeis, e linhas com barras indicam situações estressantes. As setas significam energia e fluxo de recursos. Ausência de linhas significa ausência de conexão. Podem-se usar de forma combinada e indicam o tipo de conexão².

Após ser concluída uma avaliação minuciosa, a enfermeira e família podem determinar se a intervenção é necessária ou não. As enfermeiras podem considerar de que forma vão intervir para facilitar a mudança nos domínios do cognitivo e afetivo e comportamentais de um funcionamento familiar ou apenas propor intervenções à família.

$0 \mathrm{MCIF}^{2}$ fornece meios de conceptualizar um ajuste entre os domínios do funcionamento familiar e as intervenções propostas pela enfermeira. Ele ajuda a determinar o domínio predominante do funcionamento familiar que necessita de mudança e intervenção mais adequada para efetuar a mudança naquele domínio.

A intervenção em um sistema familiar de modo a promover ou facilitar a mudança é 0 aspecto mais desafiador do trabalho clínico com as famílias. Nesse modelo, as perguntas de intervenção são em geral de dois tipos: lineares e circulares. As perguntas lineares exploram a percepção ou descrição de um problema por um membro da família, enquanto as perguntas circulares são direcionadas às explicações dos problemas, idéias, crenças, relacionamento entre os indivíduos. Os tipos de perguntas podem ser empregados para facilitar a mudança na família².

A enfermeira deve lembrar que cada família é um conjunto com seus significados e é identificada como uma unidade que cuida de seus membros e, apesar das mudanças ocorridas em sua estrutura e organização, continua sendo o principal agente socializador da criança ${ }^{11}$.

\section{PERCURSO METODOLÓGICO}

0 cenário do estudo foi o Centro Municipal de Saúde Milton Fontes Magarão que está localizado no Bairro do Engenho de Dentro do Município do Rio de Janeiro, situado na XII Região Administrativa-Área de Planejamento da Secretaria Municipal de Saúde AP 3/2, que compreende Méier e bairros adjacentes da região norte do município. Os programas desse Centro de Saúde, de saúde da criança, da mulher, do adulto e do idoso, seguem as Diretrizes da Secretaria Municipal de Saúde e são desenvolvidos por uma equipe multidisciplinar composta de médicos, enfermeiros, odontólogos, nutricionista, psicólogos, auxiliares de enfermagem, técnicos administrativos e outros.

Os alunos foram subdivididos em grupos de três, e cada subgrupo teve a oportunidade de realizar a consulta de enfermagem ao recém-nascido. 0 período do estágio supervisionado foi de cinco dias para cada subgrupo. Cada aluno teve a oportunidade de acompanhar o recém-nascido e família durante o estágio. Participaram do estudo 15 alunos, no período de agosto a dezembro de 2004. É importante ressaltar que foram atendidas as exigências da Resolução 196/96, do Conselho Nacional de Saúde ${ }^{12}$. 


\section{RESULTADOS E DISCUSSÕES}

No primeiro dia, foi apresentado o Projeto de Extensão, seus objetivos e diretrizes, e foi fornecido aos alunos um cronograma das atividades a serem desenvolvidas, sugestões de referências bibliográficas e um roteiro para a implementação do processo de enfermagem que consta das seguintes etapas: histórico de enfermagem ${ }^{7}$ que contém informações sobre a situação de saúde dos membros da família e o suporte emocional que pode ser oferecido à criança; diagnóstico de enfermagem, planejamento de enfermagem, implementação e avaliação dos resultados. Também foi entregue previamente um estudo de caso elaborado pela docente responsável pela disciplina, que consta de um roteiro de entrevista e um desenho do genograma e do ecomapa do caso em questão para facilitar a compreensão do aluno de graduação e de outros docentes da área.

Ao final do estágio com cada grupo, os alunos realizavam uma avaliação parcial sobre a implementação do processo de enfermagem utilizando o genograma e o ecomapa para a compreensão das interações familiares e os cuidados prestados à criança no contexto familiar. Esses alunos avaliavam a disciplina, as facilidades e dificuldades de cada um dos instrumentos utilizados para a avaliação e intervenção familiar e as estratégias utilizadas para a resolução dos problemas de cada família e de seu filho recém-nascido.

\section{FACILIDADES E DIFICULDADES ENCONTRADAS NA UTILIZAÇÃO DO MCAF/ MCIF}

Durante as avaliações, os alunos referiram ter dificuldade no primeiro dia do atendimento com a criança/família para a realização da entrevista e a obtenção de dados para a construção do genograma e ecomapa. Consideraram este fato inicialmente pela falta de vínculo com a família/criança, embora se apresentasse e perguntasse o nome da criança, da mãe e do outro familiar (avós, pai) que os acompanhavam, esclarecendo sobre os instrumentos e o roteiro da entrevista, e, em seguida, pela falta de habilidade em lidar com os instrumentos de forma mais aprofundada, até porque era a primeira vez que eles estavam utilizando o referido instrumento.

Uma outra dificuldade foi em relação ao tempo da entrevista na primeira consulta, que não pode ser maior que 30 minutos, porque depois disso a família logo se mostrava impaciente e demonstrando querer falar mais do que ser questionada.

0 histórico de enfermagem deve ser feito cuidadosa e sistematicamente, ao longo de vários atendimentos. E não é adequado fazer entrevistas longas e preencher questionários intermináveis no primeiro contato que se tem com a criança e a família ${ }^{7}$.

A construção do genograma pode ser iniciada logo no primeiro contato em um processo de conversa, muito mais do que entrevista, e as informações podem ser coletadas de acordo com o significado que elas têm para cada um dos familiares ${ }^{8}$.

Nas consultas subseqüentes, ficou mais fácil construir o genograma e o ecomapa, pois já existiam uma empatia e a formação do vínculo entre criança/família e discentes/ docente. 0 tempo da consulta pode ser maior que 30 minutos, já que os membros da família participam da construção do genograma e ecomapa.

Outro grupo sentiu maior dificuldade em elaborar o desenho do genograma e ecomapa, mesmo com a ajuda da família atendida por eles, alegando ser o segundo grupo a utilizar o instrumento e que tiveram pouco tempo de se apropriar dele e do estudo de caso clínico. Porém, os grupos subseqüentes já traziam o genograma e o ecomapa com a escrita e o desenho mais elaborado, pois conseguiam envolver cada um dos membros da família. 0 processo de representação do genograma da criança pela família pode resultar em desdobramentos, tais como: promoção saúde familiar, ensino, conscientização dos membros familiares e o empoderamento desta, permitindo aos indivíduos falar sobre sua própria história de vida ${ }^{9}$.

A partir da segunda consulta fica mais fácil a aplicação do instrumento para a construção do genograma e ecomapa no momento de avaliação familiar. Podemos observar que, em outros estudos $s^{4-10}$ que utilizaram o genograma e o ecomapa, foi considerada fácil sua aplicação, pois eles propiciam uma visibilidade ampla das relações familiares.

Na maioria das consultas, as intercorrências mais comuns encontradas no recém-nascido foram: dermatites, higiene precária, dificuldades na amamentação, o uso de chás e a automedicação para a cólica do recém-nascido, questões de gênero identificadas no cuidado à criança, práticas culturais familiar incutidas no cuidado tais como: simpatias, moedas no coto umbilical e faixas no umbigo.

0 próprio modelo indica as principais estratégias de intervenção que ocorrem durante as entrevistas. Ouvir a família permite que ela verbalize seus problemas e a orientação nas dúvidas que possam surgir durante a avaliação. Além disso, ajuda a família a descobrir soluções ${ }^{10}$.

Um dos subgrupos identificou um recém-nascido de baixopeso, e essa família foi agendada para vários encontros semanais por ser uma situação considerada de risco, e para o acompanhamento do ganho ponderal. Nas consultas posteriores, foi identificada insuficiência do ganho ponderal da criança, mesmo tendo recebido orientações dos profissionais de saúde (pediatra, nutricionista, enfermagem) e discutidas as orientações com a mãe, pai e avó. Foi realizada uma visita domiciliar pelos alunos, previamente agendada com os familiares, para compreender 0 ambiente da criança e que fatores estavam dificultando o ganho ponderal. Com o desenho do ecomapa, visualizamos a rede de suporte social que muito contribuiu para o ganho ponderal da criança.

As famílias apresentaram grande receptividade em falar e expor muitas vezes suas emoções, seus medos e as suas dificuldades em lidar com a criança, modificando toda uma rotina familiar. O MCAF tem sido um material valioso para 0 conhecimento e para a intervenção da criança e sua família.

Os alunos em seus depoimentos valorizaram a utilização do instrumento, pois isso fez com que percebessem que, muitas vezes, as mães das crianças necessitavam de apoio especial, já que elas até sabiam sobre os cuidados adequados ao seu 
filho, porém não possuíam recursos ou apoio que tanto desejavam. Compreenderam também que a assistência à criança não deve ficar apenas na realização das orientações de uma forma verticalizada e fora do contexto familiar, já que se trata de uma questão de respeitar os direitos, crenças familiares, cidadania e, assim, garantir um cuidado integral.

Para Burd e Baptista ${ }^{3: 94}$, o desenho da árvore permite dizer:

[...] a distribuição de informações sobre os membros da familia e seus relacionamentos entre si é uma excelente fonte de hipóteses que possibilita o entendimento do contexto. [...] como mapa, fornece um resumo clínico rápido e eficiente sobre a organização e o funcionamento familiar e uma visão dos problemas em potencial.

$\mathrm{Na}$ intervenção familiar, o aluno teve a oportunidade de discutir e conhecer a cultura familiar na prática de cuidado com o seu filho, compreender como a família utiliza os recursos para enfrentar o processo saúde-doença e a busca de informação e apoio. As demandas de cuidado manifestadas pela família foram critérios para o desenvolvimento de ações de saúde efetivas sobre a criança.

Além disso, os alunos referiram que, na relação dialógica, a troca de opiniões e experiências no cuidado prestado à criança entre discente-docentes e família contribuiu para a elaboração de novos conhecimentos para a enfermagem.

Como docentes, entendemos que o Modelo de Avaliação é mais fácil se ser realizado pelo aluno. Quanto ao Modelo de Intervenção, este foi considerado complexo, pois necessita de uma seqüência maior, com a participação de toda a equipe multiprofissional no atendimento da criança e sua família em seu domicílio para troca de saberes: profissionais e familiares.

\section{CONSIDERAÇÕES FINAIS}

0 uso do genograma e do ecomapa pode servir como mais um instrumento no processo de aprendizado para o aluno de graduação e pós-graduação em enfermagem, ampliando sua visão no contexto da integralidade, do cuidado centrado na criança e família, em diferentes espaços institucionais de saúde, e que não necessariamente na atenção primária. Em todos os níveis de assistência à saúde da criança, devem-se utilizar instrumentos que possibilitem a compreensão da família, suas relações intra e extrafamiliares para o desenvolvimento de uma assistência de enfermagem de qualidade.

A avaliação da família, tanto com relação a sua estrutura quanto a sua função, é um dos elementos importantes da consulta de enfermagem e de todos os seus componentes do método científico para identificar situações de saúde/ doença, prescrever e implementar ações de enfermagem que contribuam para o apoio, promoção, prevenção, recuperação e reabilitação da criança.

Um dos momentos mais apropriados para a aplicação do MCAF deve ser o da entrevista entre o profissional e a família da criança. A entrevista consiste em uma forma específica de comunicação direcionada para conhecer a criança em seu contexto familiar e do modo como a família lida com os problemas de saúde e doença.

0 processo da entrevista para a utilização do MCAF deve ser iniciado com o entrevistador possuindo uma caneta e papel em branco, de modo que mãe e familiares da criança vejam o que está sendo escrito e desenhado e que possam participar da construção desse processo. 0 ambiente físico deve oferecer privacidade e sigilo para os familiares e contar com brinquedos para a criança, a fim de que os familiares possam se concentrar na construção do MCAF.

Os símbolos e seus respectivos significados utilizados no genograma e ecomapa auxiliam os discentes e docentes a visualizar a real necessidade da família e a importância de conhecer a formação de uma rede de suporte social, além da troca de experiências interdisciplinares, a fim de contribuir para a resolubilidade dos problemas da criança.

Embora as principais estratégias de intervenção ocorram já na entrevista, esta torna-se importante para a relação terapêutica entre os discentes/docentes e a família e a criança, de forma a propiciar a expressão de sentimentos, idéias, crenças e troca de informações.

Acreditamos que este trabalho pode contribuir para discussões e reflexões no processo de ensino-aprendizagem entre universidade-serviço de saúde e comunidade e na formação da competência do enfermeiro que atua na área da criança.

\section{Referências}

1 Ministério da Saúde (BR). Secretaria de Atenção à Saúde. Departamento de Ações Programáticas Estratégicas. Agenda de compromissos para a saúde integral da criança e redução da mortalidade infantil. Brasília (DF); 2004.

2 Wright LM, Leahey M. Enfermeiras e famílias: um guia para avaliação e intervenção na família. São Paulo(SP): Roca; 2002

3 Burd M, Baptista C. Anamnese da família: genograma e linha do tempo. In: Mello Filho J, Burd M. Doença e família. São Paulo(SP): Casa do Psicólogo; 2004. p. 92-110
4 Chazan LF Trabalhando com as famílias na atenção primária. In: Mello Filho J,Burd M. Doença e família. São Paulo(SP): Casa do Psicólogo; 2004 p.111-22

5 Braga VAB. Dor neuropática central após lesão medular traumática: capacidade funcional e aspectos sociais. Esc Anna Nery Rev Enferm 2005 dez; 9(3):404-10

6 Serafin PO, Christoffel MM.Genograma e ecomapa: elementos facilitadores da consulta de enfermagem pediátrica. [monografia] Rio de Janeiro (RJ): Faculdade de Enfermagem; 2004. 
7 Rocha SMM, Nascimento LC. Lima RAG. Enfermagem pediátrica e a abordagem da família: subsídios para o ensino de graduação. Rev Latino-am Enfermagem 2002. set/out; 10( 5):

8 Rossato LM. Dimensões do cuidado da criança com dor e sua família. Rev Min Enferm; 2004 out/dez; 8(4): 501-05.

9 Nascimento LC, Rocha SMM, Hayes VE. Contribuições do genograma e do ecomapa para o estudo de famílias em enfermagem pediátrica. Texto\&Contexto Enferm 2005 abr/jun; 14(2):280-86.
10 Filizola CLA, Ribeiro MC, Pavarini SCl. A história da família de Rubi e seu filho Leão: trabalhando com famílias de usuários com transtorno mental grave através do Modelo Calgary de avaliação e intervenção na família. Texto\&Contexto Enferm 2003. abr/jun: 12 (2):182-90

11 Elsen I, Marcon SS, Santos MR. 0 viver em família e sua interface com a saúde e a doença. Maringá (PR): EdUEM; 2002.

12. Ministério da Saúde (BR). Conselho Nacional de Saúde. Diretrizes e normas regulamentadoras de pesquisas envolvendo seres humanos. Resolução CNS n¹96, de 10 de outubro de 1996. InfEpidemiol SUS 1996; 5 (2 supl 3): 13-41. 